\title{
EDUKASI MANFAAT PIJAT BAYI, UPAYA MENINGKATKAN KESEHATAN PADA BAYI SELAMA MASA PANDEMI COVID-19 DI DESA TELAGAWARU LOMBOK BARAT
}

\author{
Catur Esty Pamungkas ${ }^{1)}$, Desi Rofita ${ }^{1)}$, Siti Mardiyah WD'), Alika Biantari Maharani'1), \\ Yuyun Gustiana ${ }^{1)}$, Annisa ${ }^{1)}$ \\ 1)Program Studi S1 Kebidanan, Universitas Muhammadiyah Mataram, Mataram, NTB, \\ Indonesia \\ Corresponding author : Catur Esty Pamungkas \\ E-mail : catur.esty@gmail.com
}

\section{Diterima 26 November 2021, Disetujui 27 November 2021}

\begin{abstract}
ABSTRAK
Pijat bayi merupakan upaya meningkatkan kesehatan pada bayi balita pada upaya promotif terutama pada masa pandemi covid19, Pijat merupakan terapi sentuh tertua dan terpopuler yang dikenal. Pijat bertujuan untuk menghilangkan rasa sakit dan mengembalikan tubuh menjadi segar kembali. Sentuhan pijat bayi akan merangsang produksi hormon betha endorprin yang akan membantu mekanisme pertumbuhan dan merangsang produksi hormon oksitosin dan menurunkan produksi hormon kortisol sehingga bayi dan balita menjadi rileks dan tenang sehingga perkembangannya akan lebih optimal. Selain itu pijat memiliki beberapa efek positif dalam hal penambahan berat badan, pola tidur yang lebih baik, peningkatan perkembangan neuromotorik, ikatan emosional yang lebih baik, penurunan tingkat infeksi nosokomial salah satunya common cold. Solusi permasalahan yang ditawarkan yaitu edukasi manfaat pijat bayi untuk meningkatkan kesehatan bayi selama masa pandemia Covid-19. Setelah diberikan edukasi tentang manfaat pijat bayi, ibu balita dibekali modul yang dapat dipelajari di rumah dapat mempraktikan pijat bayi di rumah. Jumlah responden yang mengikuti kegiatan ini sebanyak 11 ibu yang memiliki bayi. Hasil pengabdian didapatkan pengetahuan ibu meningkat tentang pijat bayi yaitu sebanyak $46 \%$.
\end{abstract}

Kata kunci: pijat bayi; balita; pandemi covid19

\begin{abstract}
Baby massage is an effort to improve the health of infants under five in promotive efforts, especially during the covid19 pandemic. Massage is the oldest and most popular touch therapy known. Massage aims to relieve pain and restore the body to be fresh again. The touch of a baby massage will stimulate the production of beta-endorphins which will help the growth mechanism and stimulate the production of the hormone oxytocin and reduce the production of the hormone cortisol so that babies and toddlers become relaxed and calm so that their development will be more optimal. In addition, massage has several positive effects in terms of weight gain, better sleep patterns, increased neuromotor development, better emotional bonds, decreased levels of nosocomial infections, one of which is the common cold. The solution to the problem offered is education on the benefits of baby massage to improve the baby's health during the Covid-19 pandemic. After being given education about the benefits of baby massage, mothers of toddlers are provided with modules that can be studied at home and can practice baby massage at home. The number of respondents who participated in this activity were 11 mothers who had babies. The results of the service showed that the mother's knowledge increased about infant massage as much as $46 \%$.
\end{abstract}

Keywords: baby massage ; toddlers; the covid pandemic 19

\section{PENDAHULUAN}

Peningkatan kesehatan masyarakat yang digalakan pemerintah pada tahun 2016 dalam membentuk gerakan masyarakat hidup sehat (GERMAS) guna mewujudkan Indonesia sehat. Adapun dari tujuan diadakanya GERMAS adalah menurunkan resiko penyakit menular dan tidak menular dengan cara pemberian gizi 1000 hari pertama kehidupan, perbaikan pola konsumsi gizi seimbang, peningkatakan aktivitas fisik, meningkatkan pola hidup sehat, menjaga lingkungan sehat dan menghindari konsumsi rokok dan alkohol. Pada tahap awal, GERMAS secara nasional dimulai dengan berfokus pada tiga kegiatan, yaitu: 1) Melakukan aktivitas fisik 
30 menit per hari, 2) Mengonsumsi buah dan sayur; dan 3) Memeriksakan kesehatan secara rutin. GERMAS merupakan gerakan nasional yang diprakarsai oleh Presiden RI yang mengedepankan upaya promotif dan preventif, tanpa mengesampingkan upaya kuratif-rehabilitatif dengan melibatkan seluruh komponen bangsa dalam memasyarakatkan paradigma sehat (Kemenkes, 2016).

Mendukung GERMAS, pijat bayi merupakan upaya meningkatkan kesehatan pada bayi balita pada upaya promotif terutama pada masa pandemi covid19, Pijat merupakan terapi sentuh tertua dan terpopuler yang dikenal. Pijat bertujuan untuk menghilangkan rasa sakit dan mengembalikan tubuh menjadi segar kembali. Pijat dapat diterapkan pada semua usia baik dari bayi sampai dewasa. Bayi setelah lahir perlu mendapat sentuhan dari pijatan agar mendapatkan jaminan adanya kontak tubuh berkelanjutan yang dapat dipertahankan perasaan aman pada bayi. Pijat bayi merupakan kontak kulit melalui sentuhan dan kasih sayang dari orang tua yang bertujuan meningkatkan kontak fisik dan psikologis antara ibu dan bayi (Fauziandari, 2019).

Sentuhan pijat bayi akan merangsang produksi hormon betha endorprin yang akan membantu mekanisme pertumbuhan dan merangsang produksi hormon oksitosin dan menurunkan produksi hormon kortisol sehingga bayi dan balita menjadi rileks dan tenang sehingga perkembangannya akan lebih optimal. Pijat dan sentuhan kasih sayang yang dimulai pada usia dini dapat meningkatkan kualitas hidup anak dan orang tua. Sehingga pijat bayi merupakan salah satu cara yang baik untuk memberikan stimulasi pertumbuhan dan perkembangan bayi dan balita (Fauziandari, 2019).

Seorang anak membutuhkan dukungan untuk mencapai pertumbuhan dan perkembangan sesuai usianya, melalui program 1000 Hari Pertama Kehidupan pemantuan tumbuh kembang dimulai sejak dalam kandungan, kecukupan nutrisi dan stimulasi yang mendukung pertumbuhan dan perkembangan sampai 2 tahun pertama kehidupan anak (Kementerian Koordinator Bidang Kesejahteraan Rakyat, 2013).

Salah satu upaya preventif untuk kelola stres pada bayi yaitu dengan baby massage. Baby Massage sendiri adalah sentuhan terhadap anak dari usia 0 bulan sampai 12 bulan. Di Indonesia pelaksanaan pijat bayi di masyarakat desa masih dipegang perannya oleh dukun bayi. Selama ini, pemijatan tidak hanya dilakukan pada saat bayi sehat, tetapi juga pada bayi rewel dan sudah menjadi rutinitas perawatan bayi setelah lahir (Aminarti, 2013).

Bayi dapat tumbuh dan berkembang dengan baik jika kebutuhan dasarnya terpenuhi, yaitu asah, asih dan asuh. Kebutuhan asah adalah kebutuhan akan stimulasi dini. Pemberian stimulasi dini yang sesuai akan memungkinkan terbentuknya etika, kepribadian yang baik, kecerdasan, kemandirian, keterampilan dan produktivitas yang baik (Heath A and Bainbridge N, 2007).

Penelitian yang dilakukan (Irva, Hasanah and Woferst, 2014) pijat bayi memberikan manfaat meningkatkan berat badan sebesar 700 gram selama 2 minggu pemijatan. Pemijatan pada bayi akan merangsang nervus vagus yang akan menyebabkan peningkatan kadar enzim penyerapan gastrin dan insulin lebih maksimal. Aktifitas nervus vagus akan meningkatkan peristaltik usus, sehingga pengosongan lambung lebih cepat dengan demikian akan merangsang nafsu makan bayi untuk makan lebih lahap dalam jumlah yang cukup. Efektifitas pijat bayi memberikan manfaat pada perkembangan motorik sangat baik pada anak usia 8-28 hari dibandingkan dengan anak yang tidak diberikan stimulasi pijat bayi (Rizki, 2017).

Beberapa penelitian lain menjelaskan bahwa pijat bayi secara signifikan dapat meningkatkan berat badan pada bayi preterm jika dibandingkan dengan kelompok kontrol. Penelitian ini sejalan dengan penelitian yang dilakukan oleh Dasuki (2010) menyatakan bahwa pijat bayi dapat menaikkan berat badan pada bayi. Penelitian yang sama dilakukan oleh Purnamasari (2011) menjelaskan bahwa pada bayi 4 bulan terdapat kenaikan berat badan bayi yang signifikan. Penelitian yang dilakukan oleh Sari (2014) menyatakan bahwa pijat bayi memiliki efek terhadap pertumbuhan dan perkembangan bayi. Penelitian yang dilakukan Murtiningsih, Wijaya and Permadi (2019) pijat bayi dapat meningkatkan motorik kasar duduk dan merangkak mandiri pada bayi usia 9 bulan. Banyak manfaat dari intervensi pijat bayi ini bisa diterapkan dari ibu ke anak dengan pelatihan pijat bayi secara berkelanjutan.

Selain itu pijat memiliki beberapa efek positif dalam hal penambahan berat badan, pola tidur yang lebih baik, peningkatan perkembangan neuromotorik, ikatan emosional yang lebih baik, penurunan tingkat infeksi nosokomial salah satunya common cold (Kulkarni et al, 2010). Common cold yang juga disebut Infeksi Saluran Pernapasan Atas (ISPA) adalah infeksi primer di nasofaring dan hidung yang sering mengeluarkan cairan, penyakit ini banyak dijumpai pada bayi dan anak (Ngastiyah, 2011). Terapi pijat telah 
menunjukkan efek positif untuk mengatasi permasalahan pada bayi prematur, masalah pencernaan termasuk sembelit dan diare, serta untuk penyakit saluran pernapasan seperti asma dan common cold (Diego, 2019).

Pada bayi usia 0-3 tahun, gerakan yang dilakukan lebih mendekati usapan-usapan halus, tekanan ringan, dan dengan tekanan, disarankan pemijatan dilakukan sekitar 15 menit, sesuai usia bayi dan waktu dapat ditingkatkan sesuai kebutuhan (Roesli, 2016). Pijat bayi yang dilakukan sebelum tidur malam dapat meningkatkan lamanya tidur malam pada bayi usia 3-6 bulan (Permata, Fisioterapi and Abdurrab, 2017).

Notoatmodjo (2012) menjelaskan bahwa setelah manusia mendapatkan informasi atau pelatihan maka akan diolah lebih lanjut dengan memikirkan, mengolah, mempertanyakan, menggolongkan, dan merefleksikan. Pengetahuan pengasuh yang mengalami peningkatan setelah dilakukan pelatihan pijat bayi dapat direfleksikan dengan sikap yang mendukung pijat bayi dan praktik pijat bayi. Pengetahuan ibu tentang pijat bayi meliputi tentang pengertian pijat bayi, manfaat pemijatan, waktu yang tepat untuk pemijatan, tempat yang nyaman untiuk pemijatan dan Teknik pijat bayi. Adanya pemberian pelatihan dan informasi tentang pijat bayi dapat meningkatkan pengetahuan pengasuh tentang pijat bayi. Hal ini dapat menentukan sikap pengasuh dalam melakukan perilaku pijat bayi terhadap bayi yang diasuhnya.

\section{METODE}

Telagawaru Kecamatan Labuapi Kabupaten Lombok Barat. Kegiatan pengabdian mengadopsi langkah-langkah action research yang terdiri dari 4 (empat) tahapan, yaitu : perencanaan, tindakan, observasi dan evaluasi, dan refleksi (Yaumi, Muhammad dan Damopolii, 2014). Memberikan edukasi tentang manfaat pijat bayi sebagai upaya peningkatan kesehatan selama masa pandemi Covid-19. Metode yang dilakukan yaitu memberikan edukasi edukasi tentang manfaat pijat bayi sebagai upaya peningkatan kesehatan pada ibu. Melakukan evaluasi pengetahuan ibu tentang manfaat pijat bayi sebagai upaya peningkatan kesehatan

\section{HASIL DAN PEMBAHASAN Perencanaan}

a. Koordinasi dan pemberian informasi kegiatan pengabdian kepada mitra, dan perangkat desa. Tim pelaksana diundang untuk mengadakan pertemuan persiapan pelaksanaan dengan melibatkan mahasiswa S1 Kebidanan sebanyak 3 orang. Pada pembekalan ini juga menjelaskan rangkaian kegiatan secara teknis pelaksanaan pengabdian. Didukung dengan penjelasan yang dilakukan (Priyoto, 2014) Seseorang dapat melakukan suatu tindakan sesuai dengan tujuan, jika orang tersebut memahami dengan benar bahwa tindakan yang dilakukan merupakan tindakan yang wajib dikerjakan.

b. Sosialisasi kegiatan pengabdian pada desa mitra, Sosialisasi dilakukan dalam bentuk koordinasi dengan mengundang kader posyandu. Kegiatan sosialisasi dilakukan oleh Tim Pengabdian. Rencana sosialisasi akan tetap memperhatikan protokol kesehatan dengan selalu menggunakan masker dan menjaga jarak. Sosialisasi dilakukan mengingat pentingnya peran aktif kader dalam merekrut peserta dalam keikutsertaan pengabdian berdasarkan kriteria ibu dan balita dalam kondisi sehat, bersedia mengikuti kegiatan hingga akhir dan bertempat tinggal di wilayah Desa Telagawaru Kecamatan Labuapi Kabupaten Lombok Barat.

c. Persiapan kegiatan pengabdian tanggal, lokasi pengabdian diupayakan ditempat yang luas dan memiliki kapasitas cukup untuk diterapkannya protokol kesehatan dan alat dan bahan yang dibutuhkan.

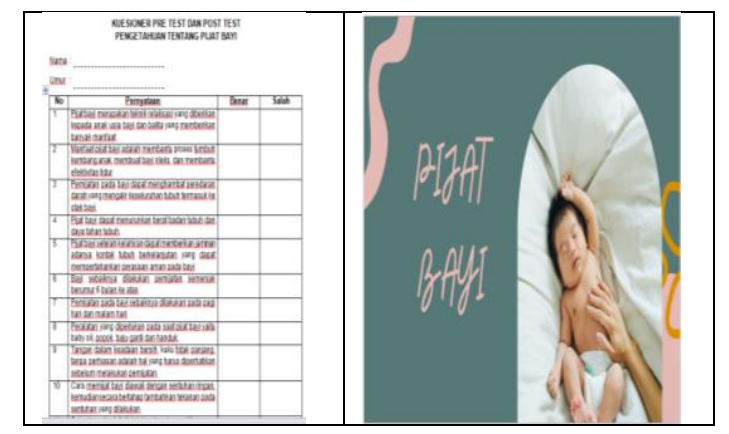

Gambar 1. Kuesioner dan modul pijat bayi

\section{Tindakan}

Pelaksanaan kegiatan pengabdian tentang pemberian edukasi pijat bayi sebagai upaya meningkatkan kesehatan bayi dimasa Pandemi Covid19, di Desa Telagawaru Kecamatan Labuapi Kabupaten Lombok Barat dilaksanakan pada tanggal Sabtu, 18 September 2021 bertempat di Sekretariat Kampung (KB) di Desa Telagawaru. Hasil kegiatan yaitu :

a. Distribusi frekuensi berdasarkan karakteristik responden dalam kegiatan pengabdian, yaitu: 
Tabel 1. Distribusi frekuensi berdasarkan usia dan jenis kelamin anak

\begin{tabular}{lccc}
\hline \multirow{2}{*}{ Usia } & \multicolumn{2}{c}{ Jenis Kelamin } & \multirow{2}{*}{ Total } \\
\cline { 2 - 3 } & Perempuan & Laki-laki & \\
\hline 0-1 Tahun & 4 & 2 & 6 \\
\hline$>1-2$ Tahun & 3 & 2 & 5 \\
\hline Total & & & 11 \\
\hline
\end{tabular}

Berdasarkan tabel 1. Didapatkan jumlah responden minoritas yaitu anak laki-laki yang memiliki usia 1-2 tahun yaitu 2 orang, kemudian jumlah responden terbanyak pada anak perempuan usia 0-1 tahun sebanyak 4 orang.

b. Distribusi frekuensi berdasarkan pengetahuan ibu tentang manfaat pijat bayi terhadap peningkatan kesehatan bayi pada masa pandemi.

Tabel 2. Distribusi frekuensi berdasarkan pengetahuan ibu

\begin{tabular}{lcccc}
\hline \multirow{2}{*}{ Pengetahuan } & \multicolumn{2}{c}{ Pre Test } & \multicolumn{2}{c}{ Post Test } \\
\cline { 2 - 5 } & $\mathrm{n}$ & $\%$ & $\mathrm{n}$ & $\%$ \\
\hline Baik & 4 & 36,4 & 9 & 82 \\
\hline Cukup & 6 & 54,6 & 2 & 18 \\
\hline Kurang & 1 & 9 & 0 & 0 \\
\hline
\end{tabular}

Berdasarkan tabel 2 didapatkan bahwa pengetahuan responden mayoritas memiliki pengetahuan cukup pada pre-test sebanyak 6 orang $(54,6 \%)$ sedangkan pengetahuan kurang hanya 1 orang $(9 \%)$ sedangkan pengetahuan responden pada post test mengalami peningkatan, jumlah responden dengan pengetahuan baik sebanyak 9 orang $(82 \%)$ sedangkan responden dengan pengetahuan cukup sebanyak 2 orang (18\%). Berikut pre-test dan post-test pengetahuan ibu tentang manfaat pijat bayi:

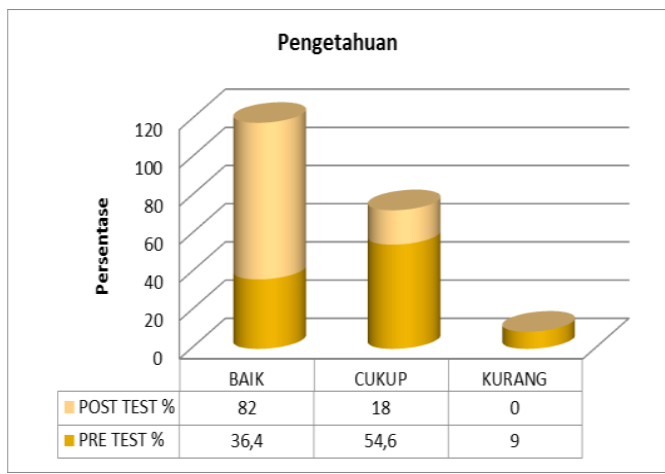

Gambar 2. Diagram pre-test dan post-test pengetahuan ibu tentang manfaat pijat bayi c. Tim memberikan paket modul dan kuesioner tentang manfaat pijat bayi

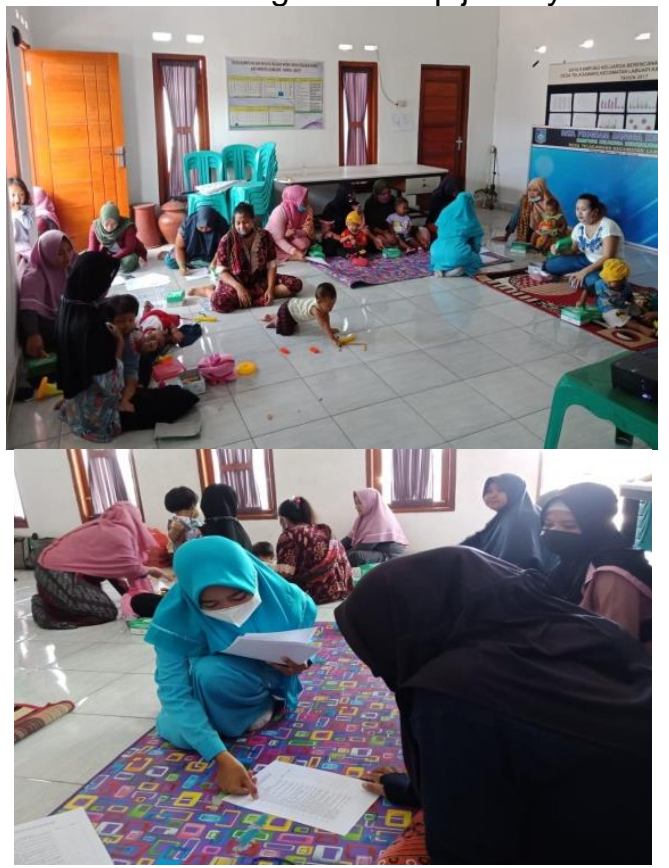

Gambar 3. Pembagian modul dan kuesioner tentang manfaat pijat bayi

d. Tim memaparkan materi manfaat pijat bayi yang telah dirangkum dalam power point menggunakan media LCD. Materi yang dipaparkan yaitu pengertian pijat bayi, manfaat pijat bayi, waktu dan suasana yang tepat untuk pijat bayi, persiapan pijat bayi, posisi dalam melakukan pijat bayi, hal-hal yang perli diperhatikan dan dihindari dalam pijat bayi, serta pedoman dalam melakukan pijat bayi.

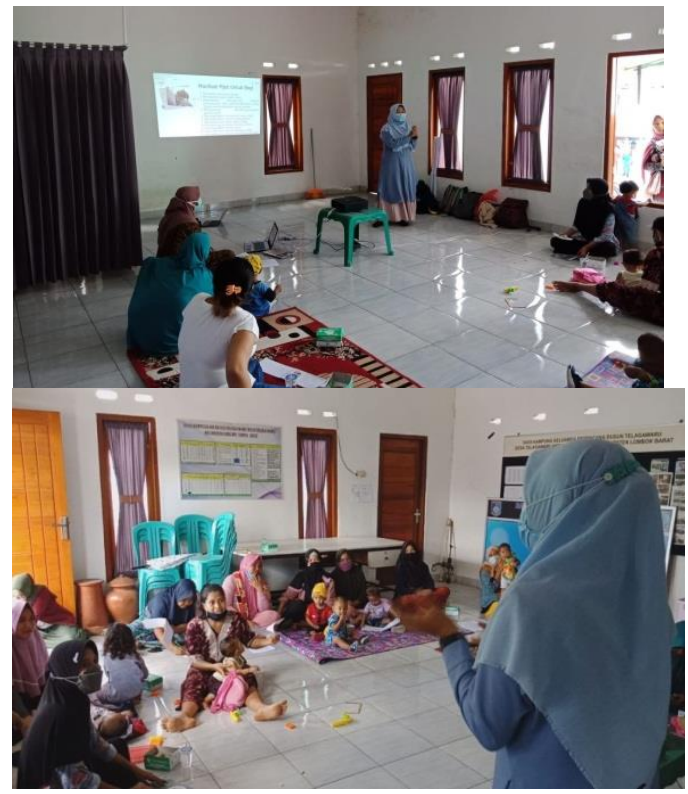

Gambar 4. Pemaparan Teori manfaat pijat bayi 


\section{Observasi}

Observasi dilakukan terhadap pengetahuan ibu tentang manfaat pijat bayi dalam meningkatkan kesehatan dan langkah-langkah pijat bayi yang benar. Ibu diminta mempraktikkan pijat bayi secara mandiri setelah pemaparan materi oleh narasumber.

\section{Evaluasi}

Evaluasi tingkat pemahaman dan kemampuan pijat bayi diukur dengan Instrumen berupa kuesioner pre test dan post test dari sebelum dilakukan pemijatan dan setelah dilakukan pemijatan bayi yang dimiliki masing-masing di Desa Telagawaru Kecamatan Labuapi Kabupaten Lombok Barat.

\section{Kontribusi Mitra Dalam Kegiatan}

Mitra dalam kegiatan pengabdian berperan aktif

1. Perangkat desa aktif dalam memfasilitasi kader yang ditunjuk dalam kegiatan pengabdian dan lokasi tempat pelaksanaan pengabdian

2. Kader, mahasiswa dan tim pengabdian aktif berdiskusi dalam perencanaan kegiatan dan alat dan bahan serta teknik pelaksanaan kegiatan

3. Keikutsertaan aktif dan antusias juga terlihat pada responden yang hadir datang tepat waktu dan mengikuti kegiatan hingga selesai, responden juga memperhatikan protokol kesehatan selama jalannya kegiatan pengabdian.

\section{Potret Permasalahan Lain Dalam Kegiatan}

Potret permasalahan lain yang terekam selama kegiatan pengabdian:

a. Kurangnya akses pelayanan kesehatan dimasa pandemi, sehingga bendampak kurangnya pemantauan kesehatan pada bayi.

b. Masyarakat ingin mendapatkan kegiatan serupa secara berkelanjutan sebagai upaya meningkatkan kesehatan bayi.

\section{Simpulan Dan Saran}

Tim Pengabdian Masayarakat sudah memberikan informasi dan edukasi manfaat pijat bayi selama masa pandemi Covid-19 pada ibu di desa telagawaru lombok barat Pada 11 responden. Tim Pengabdian sudah memberikan pre test dan post test dalam kegiatan ini didapatkan pengetahuan ibu tentang manfaat pijat bayi meningkat $46 \%$ yaitu Baik. Peserta dibekali modul manfaat pijat bayi yang dapat dibawa pulang sebagai bahan edukasi peserta di rumah.

\section{UCAPAN TERIMAKASIH}

Tim penulis mengucapkan terima kasih kepada Kementrian Riset dan Teknologi/Badan Riset dan Inovasi Nasional (Ristek-BRIN) yang telah mendanai kegiatan pengabdian ini sehingga terlaksana dengan baik. Lembaga Penelitian dan Pengabdian Masyarakat Universitas Muhammadiya dan Mitra Pengabdian Masyarakat yang telah mendukung dan memfasilitasi kegiatan pengabdian sehingga berjalan dengan lancar.

\section{DAFTAR RUJUKAN}

Aminarti, D. (2013) Pijat dan senam untuk bayi \& balita. Yogyakarta: Brilliant Books.

Dasuki. (2010). Pengaruh Pemijatan terhadap Kenaikan Berat Badan dan Lama Tidur Bayi Usia 1 sampai 3 Bulan. Jurnal Penelitian Kesehatan Suara For Ikes Vol II.

Diego, MA. Field, T. Hernandez, M. (2014). Preterm Infant Weight Gain is Increased by Massage Therapy and Exercise Via Defferent Underlying Mechanisms. Early Human Development. doi 10.1016/j.earlhumdev.2014.01.009.

Fauziandari, E. N. (2019). Stimulasi tumbuh kembang bayi dan balita dengan pijat bayi pada ibu ibu di masjid al rubaian. Pengabdian Masyarakat Karya Husada, 1(2), 22-26.

Heath A and Bainbridge N (2007) Baby Massage: Kekuatan Menenangkan dari Sentuhan. Jakarta: Dian Rakyat.

Irva, T. S., Hasanah, O.- and Woferst, R.(2014) 'Pengaruh terapi pijat terhadap peningkatan Berat badan bayi', Jurnal Online Mahasiswa (JOM) Bidang IImu Keperawatan, 1(2), pp. 1-9. Available at:

https://jom.unri.ac.id/index.php/JOMPS IK/article/view/4142/4035.

Kementerian Koordinator Bidang

Kesejahteraan Rakyat (2013)

'Kerangka Kebijakan Gerakan Nasional

Percepatan Perbaikan Gizi dalam Rangka Seribu Hari Pertama Kehidupan (Gerakan 1000 HPK)', p. 71.

Kementrian Kesehatan RI (2016) 'Pedoman pelaksanaan stimulasi, deteksi, dan intervensi tumbuh kembang anak.'

Kulkarni et al. 2010. Massage and Touch Therapy in Neonates: The Current Evicence Vol. 47. Journal Indian Pediatrics.

Murtiningsih, M., Wijaya, I. P. D. and Permadi, A. W. (2019) 'Pijat Bayi Untuk Meningkatkan Motorik Kasar Duduk Dan Merangkak Mandiri Pada Bayi Usia 
9 Bulan Di Upt Kesmas Sukawati I', Jurnal Kesehatan Terpadu, 3(1), pp. 22-25. doi: 10.36002/jkt.v3i1.710.

Ngastiyah. 2011. Perawatan Anak Sakit. Edisi 2. Jakarta : EGC

Notoatmodjo, S. (2012). Promosi Kesehatan dan IImu Perilaku. Jakarta : Rineka Cipta.

Permata, A., Fisioterapi, P. S. D. and Abdurrab, U. (2017) 'Pengaruh Pijat Bayi Terhadap Peningkatan Lama Tidur Malam Pada Bayi 3 - 6 Bulan Effects of Baby Massage to Improvement of Long Night Sleep on Baby 3-6 Months', (2), pp. 37-45.

Purnamasari, D. (2011). Panduan Pijat Praktis Balita Anda agar Cerdas dan Sehat. Yogyakarta : Pustaka Solomon.

Rizki, L. (2017) 'Efektivitas Pijat Bayi Pada Perkembangan Motorik pada Bayi Usia 8-28 hari', Maternal and Neonatal Health Journal, 1(2), pp. 76-80.

Roesli, U. (2016) Pedoman Pijat Bayi. Jakarta: Trubus Agriwidya.

Sari, P.E.K. (2014). Efektivitas Pijat Bayi terhadap Pertumbuhan dan Perkembangan Bayi Usia 6 Bulan di Kelurahan Bintaro Jakarta. Skripsi. Jakarta : Universitas Islam Negeri Syarif Hidayatullah.

Yaumi, Muhammad dan Damopolii, M. (2014) Action Research: Teori, Model, dan Aplikasi. Jakarta: Kencana. 